\title{
How Endogenous Motivations Influence User Intentions: Beyond the Dichotomy of Extrinsic and Intrinsic User Motivations
}

\author{
YOGESH MALHOTRA, DENNIS F. GALLETTA, AND \\ LAURIE J. KIRSCH
}

Yogesh Malhotra is an Associate Professor of Accounting and Information Systems at the Martin J. Whitman School of Management of Syracuse University. He holds a Ph.D. from the University of Pittsburgh. Dr. Malhotra has taught and lectured as invited faculty at Kellogg, Carnegie Mellon, INSEAD (France), and Queen's (Canada). His research focus is on information systems and control issues, why knowledge management systems fail, and risk management to prevent such failures. The 2008 Report of the Association to Advance Collegiate Schools of Business (AACSB) International Impact of Research Task Force lists his research in information systems as an "exemplar" of how basic research can have substantive impact on actual practice. He is ranked among the world's most influential knowledge management experts in scientific citation impact studies and industry panels and surveys. Owing to his research, Dr. Malhotra is ranked among the top four, six, and three MIS scholars worldwide in studies on knowledge management by, respectively, the American Society for Information Science and Technology, University of Minnesota, and Drexel University. He has received invited research grants from the United Nations and Intel Corporation. His professional experience includes top management advisory, consulting, and executive leadership roles with the United Nations, world governments, and global hi-tech, finance and banking, and management consulting corporations and Fortune 100 across the United States, North America, Europe, and Asia.

Dennis F. Galletta is an AIS Fellow, AIS President, and Professor of Business Administration at the Katz School, University of Pittsburgh. He obtained his Ph.D. in MIS from the University of Minnesota. His research interests cover end-user behavior, attitudes, and performance. His articles have appeared in journals such as Management Science, Information Systems Research, Journal of Management Information Systems, Communications of the ACM, Decision Sciences, Data Base, Information and Management, European Journal of Information Systems, and Journal of AIS. He has served on several editorial boards, including Information Systems Research, MIS Quarterly, Data Base, Canadian Journal of Administrative Sciences, and Information Systems and e-Business Management. His research studies have also been featured in outlets such as BusinessWeek, Wall Street Journal, Computerworld, and CNN. He recently edited a two-volume collection of research on human-computer interaction in the MIS field for Vladimir Zwass's series Advances in Management Information Systems (AMIS). He taught undergraduate information systems courses during the fall 1999 Semester at Sea voyage, served as the ICIS treasurer from 1994 to 1998, was a member of AIS council representing the Americas (1996-97), chaired the first Americas Conference for AIS (AMCIS), was program cochair for both ICIS (2005)

\footnotetext{
Journal of Management Information Systems / Summer 2008, Vol. 25, No. 1, pp. 267-299.

(C) 2008 M.E. Sharpe, Inc.

0742-1222 / $2008 \$ 9.50+0.00$.

DOI 10.2753/MIS0742-1222250110
} 
and AMCIS (2003), and served as editor-in-chief of ISWorld. He will cochair the ICIS 2008 Consortium in Paris and ICIS 2011 in Shanghai.

LaURIE J. KIRsch is a Professor of Business Administration at the University of Pittsburgh. She holds a Ph.D. from the University of Minnesota. Dr. Kirsch's research explores the exercise of control and the transfer of knowledge in the IS context, examining how stakeholders can better manage large IS initiatives that span departments, organizations, and geographies. Her research has been funded by the Society for Information Management and the National Science Foundation. Dr. Kirsch has published her research in leading scholarly journals such as MIS Quarterly, Management Science, Organization Science, Information Systems Research, and Accounting, Management and Information Technologies. She is active in the Association for Information Systems, the International Conference on Information Systems, and the Academy of Management. Dr. Kirsch serves, or has served, on the editorial boards of Information Systems Research, MIS Quarterly, Management Science, Information and Organization, Decision Sciences, MIS Quarterly Executive, and Journal of Strategic Information Systems.

ABSTRACT: Information technology (IT) adoption research recognizes theoretical limitations in discerning if and when user behavior results from perceived external influences or from personal volition. A clear understanding of this issue requires a precise distinction between mandatory and volitional behaviors. Consistent with organismic integration theory (OIT), this study situates the locus of user motivations inside the user. Drawing upon an endogenous view of behaviors, this research makes three key contributions. First, it develops the theoretical basis for clearly discerning if and when behavior results from perceived external influences or from personal volition. Specifically, it examines how endogenous psychological feelings of autonomy, freedom, conflict, and external pressure can predict and explain user intentions. Second, it proposes that behavior may result from combinations of perceived external influences and personal volition. Recognizing how such "collections of motivations" together influence behavior advances our understanding beyond the "dichotomy" of extrinsic versus intrinsic motivations often adopted in prior research. Third, it proposes that some desired behaviors may be thwarted or impeded by a conflict between perceived external influences and personal volition. The theoretically grounded research model was empirically validated in a field study on Blackboard, a Web-based education platform at a large university. Data collected from a sample of 211 users were tested using structural equation models of initial system adoption and experienced use. Empirical support was found for the proposed model and related hypotheses. The results of this study advance our understanding about user motivations for adopting IT.

KEY WORDS AND PHRASES: endogenous motivations, locus of causality, organismic integration theory, system adoption, system use, system user motivations, technology-enabled learning.

"Do not hire a man who does your work for money, but him who does it for the love of it."

—Henry David Thoreau 
"The more I want to get something done, the less I call it work."

-Richard Bach

"My work is a game, a very serious game."

-M.C. Escher

INFORMATION TECHNOLOGY (IT) ADOPTION RESEARCH has helped us understand more thoroughly a variety of antecedents to behavioral intentions. The basic, original antecedents of perceived usefulness and ease of use have accounted for significant variance over the years. When studies have investigated the extent to which the models can be expanded to explain more variance, much of the variance continues to be accounted for by those "user beliefs" [60]. Being dependent upon influences and stimuli external to the user, they also seem to represent exogenous antecedents of behavior [23].

However, recent research has questioned if external stimuli and social influences, such as subjective norms and managerial mandates, govern user intentions as expected $[7,18,35,41,62]$. Further, information systems (IS) research recognizes that the same external influences and stimuli may be experienced differently by different users [19, $35,39,62]$. Despite the existence of the same external stimuli, some users show willing adoption of a system while others exhibit resistance [35, 40].

What is missing is an endogenous theoretical understanding-that is, how users' internal perceptions of autonomy, freedom, conflict, and feelings of external pressure affect intentions. ${ }^{1}$ Because they are more proximal antecedents, endogenous motivations should promise more direct and immediate prediction and explanation of user intentions. Toward this goal, the current study develops and empirically tests a model of system users' endogenous motivations based on Deci and Ryan's [23] organismic integration theory (OIT).

OIT's focus is on how a user's internal psychological perceptions about autonomy shape his or her intentions and behaviors. Knowing the endogenous origins can help explain and predict individual-level differences in intentions and behaviors across a population of users. It can also explain why new technologies are more readily accepted by some users and less willingly by others, consequently resulting in different behavioral outcomes.

Understanding how endogenous motivations influence user intentions, beliefs, and behaviors is important for both theoretical and practical reasons. Theoretical benefits include enrichment of the user motivation literature by addressing an area that has received sparse attention. Practical benefits include helping managers identify effective strategies for motivating employees to accept and use IT by supporting and facilitating their endogenous tendencies. Such strategies are expected to include greater volitional persistence of usage behavior, better relationships in one's social groups, more effective behavioral performance, and greater well-being [25].

\section{Extrinsic-Intrinsic Dichotomy in Prior Research}

The "Motivational model" PRoposed by Davis et al. [19] is the dominant perspective underlying our understanding about user motivations [60]. When conceiving that 
model, Davis et al. [19] asked if people used computers at work more because they are useful or because they are enjoyable to use. Extrinsic motivation was defined as "the performance of an activity because it is perceived to be instrumental in achieving valued outcomes that are distinct from the activity itself, such as improved job performance, pay, or promotions" [19, p. 1112]. Davis et al. distinguished it from intrinsic motivation as follows: "While extrinsic motivation influences behavior due to the reinforcement value of outcomes, intrinsic motivation refers to the performance of an activity for no apparent reinforcement other than the process of performing an activity per se" [19, p. 1112]. Emphasizing the mutually exclusive nature of the two motivation types, they observed: "Within this dichotomy, perceived usefulness is an example of extrinsic motivation, whereas enjoyment is an example of intrinsic motivation" [19, p. 1112, emphasis added]. Recognizing the complex role of user motivation, Davis et al. emphasized the need for more research to understand the independent, mutually reinforcing, or countervailing effects of various motivations.

The literature suggests three important insights regarding user motivation: (1) both intrinsic and extrinsic motivation play important roles in forming users' IT adoption perceptions and affecting their adoption and use behaviors; (2) while both types of motivation are important, the same type of motivation may have differential effects across different users; and (3) different motivation types can possibly coexist to have countervailing or mutually reinforcing effects on user intentions. However, conceptualizing extrinsic motivation as perceived usefulness and intrinsic motivation as enjoyment seems to have limited our understanding of user motivation. A more generalizable conceptualization is necessary to account for users' endogenous psychological states to advance user motivation research.

The purpose of this study is to examine how endogenous psychological feelings of autonomy, freedom, conflict, and external pressure can predict and explain user intentions. In their study, Roberts et al. [44] argued that individual motivations are not independent but rather interrelated in complex ways. Recognizing how such "collections of motivations" $[25,57]$ together influence behavior advances our understanding beyond the "dichotomy" of (extrinsic versus intrinsic) motivation examined in much prior research. Specifically, our research advances theoretical understanding of "collections of motivations" wherein diverse interrelated motivations cumulatively affect behavior.

\section{Theory and Research Hypotheses}

\section{Organismic Integration Theory}

EXOGENOUS AND ENDOGENOUS MOTIVATIONS reflect two different perspectives of motivation-mechanistic and organismic, respectively [23, 48]. Mechanistic theories view extrinsically motivated activities as being motivated by rewards, and view intrinsically motivated activities as those for which the reward is in the activity [48, 54]. Consistently, IS research has characterized extrinsic motivation in instrumental terms and 
intrinsic motivation as enjoyment resulting from activities such as playing computer games $[19,60]$.

In contrast, organismic theory tends to view the individual as being volitional and initiating all behaviors [25]. OIT treats stimuli not as causes of behavior, but as affordances and opportunities that one can utilize for satisfying one's needs. It gives primacy to what one experiences as it is concerned with the subjective psychological meaning of stimuli rather than their exogenous characteristics [23]. Hence, it can help understand what the user experiences or feels and how those feelings affect intentions and behaviors.

\section{Endogenous Motivations}

OIT provides a crucial theoretical lens to understand how social values are internalized to self-regulate behavior [25]. Self-regulation of behavior is more affective than cognitive, based on self-approval or disapproval contingent on perceptions of one's own actions [23]. OIT argues that productive behavior may not only be volitionally motivated without expectation of extrinsic rewards, but may even be undermined by those rewards [25, 49]. Instead, OIT proposes the endogenous notion of volitional extrinsic motivation. For example, such internal representation may be through a user's feelings and thoughts such as "good employees do not play computer games at work." It provides a theoretical basis for recognizing that system users can possibly be autonomously extrinsically motivated without reliance on instrumental rewards.

Recognizing extrinsic motivations as independent of extrinsic rewards provides a managerial basis for guiding behavior without relying on the "carrot-and-stick" archetype. It has obvious benefits for IT productivity. It also explains how social values are appropriated and internalized in a progression from external regulation to internal regulation. External regulation implies that the individual perceives the origin of one's behavior in external influences or pressures. Internal regulation implies that the individual perceives the origin of one's behavior in one's self-that is, the specific behavior is freely chosen.

A summary comparison of exogenous motivations that have been examined in prior research and endogenous motivations that are the focus of this study is provided in Table 1.

\section{Perceived Locus of Causality}

Limitations of relying on explanations of behavior based on the absence or presence of managerial mandates and social influences have been noted in prior research [18, $19,35,62]$. In contrast, by directly examining users' psychological states in terms of perceived locus of causality (PLOC), OIT precisely explains if users feel autonomy, external pressure, or a combination. ${ }^{2}$ In internal PLOC, actors perceive themselves as the "origin" of their own behavior. In external PLOC, actors see themselves as "pawns" controlled by external forces [20]. For instance, users may be highly motivated to learn 
Table 1. Comparison of Endogenous and Exogenous Motivations

\begin{tabular}{|c|c|}
\hline Endogenous motivations & Exogenous motivations \\
\hline \multicolumn{2}{|l|}{ Conceptualization of extrinsic motivation } \\
\hline $\begin{array}{l}\text { Endogenous extrinsic motivations: } \\
\text { Consistent with the organismic integration } \\
\text { theory, extrinsic motivation represents } \\
\text { the less volitional type of extrinsic } \\
\text { motivation and corresponds to external } \\
\text { regulation of behavior. Autonomous } \\
\text { extrinsic motivation is recognized among } \\
\text { the three types of extrinsic motivations } \\
\text { with different characteristics and } \\
\text { corresponding behavioral outcomes. }\end{array}$ & $\begin{array}{l}\text { Exogenous extrinsic motivation: } \\
\text { Extrinsic motivation is typically } \\
\text { conceptualized in terms of the instrumental } \\
\text { notion of perceived usefulness. It is } \\
\text { typically represented as being caused by } \\
\text { "external" stimuli such as tangible rewards } \\
\text { and job performance. A notion of } \\
\text { autonomous or volitional extrinsic } \\
\text { motivation is therefore infeasible. Hence, } \\
\text { work must be extrinsically motivated. }\end{array}$ \\
\hline Conceptualization of intrinsic motivation & \\
\hline $\begin{array}{l}\text { Endogenous intrinsic motivation: } \\
\text { Consistent with the organismic integration } \\
\text { theory, intrinsic motivation represents } \\
\text { the pursuit of optimal challenges that } \\
\text { enhance self-learning, self-development, } \\
\text { and self-growth. Hence, fun and } \\
\text { enjoyment are the creations of the } \\
\text { human psyche rather than of any } \\
\text { "external" stimuli or exogenous artifacts. } \\
\text { Hence, (what may seem as) hard labor } \\
\text { or challenge (productive work or } \\
\text { nonwork) can be fun. }\end{array}$ & $\begin{array}{l}\text { Exogenous intrinsic motivation: } \\
\text { Intrinsic motivation is typically } \\
\text { conceptualized in terms of fun and } \\
\text { enjoyment derived from "external" stimuli } \\
\text { and exogenous artifacts such as computer } \\
\text { games. These notions of fun and } \\
\text { enjoyment are typically related to pursuit } \\
\text { of hedonistic pleasure. This } \\
\text { conceptualization resulted from the } \\
\text { original "dichotomy" of intrinsic and } \\
\text { extrinsic motivations. Hence, productive } \\
\text { work cannot be fun. }\end{array}$ \\
\hline
\end{tabular}

and use a new IT out of curiosity and self-interest. Alternatively, their self-perceived reason for motivation may be the approval of a supervisor.

PLOC pertains to the self; the degree to which action is initiated from and endorsed by the self describes the relative autonomy of the act [46]. A user may feel compulsion even when environmental pressures (e.g., external mandates or social norms) are clearly absent. Users' feelings affect behavior regardless of the presence of external forces. Examples would include behaving from guilt or obligation, rather than out of choice. Hence, OIT argues that the user's perceptions of volition and compulsion are functions of PLOC rather than any "external stimuli." Volition is characterized as internal PLOC while compulsion is characterized as external PLOC.

Ryan and Connell [46] developed a methodology for examining internal and external PLOC that is considered crucial for studying intrinsic versus extrinsic motivation [25]. Different types and levels of PLOC have qualitatively different influences on behavior and have a cumulative influence on intentions [23]. An example is the state of ambivalence denoted by introjected PLOC wherein a user wants to do one thing but the system forces him or her to do another. OIT affords the recognition of differential 


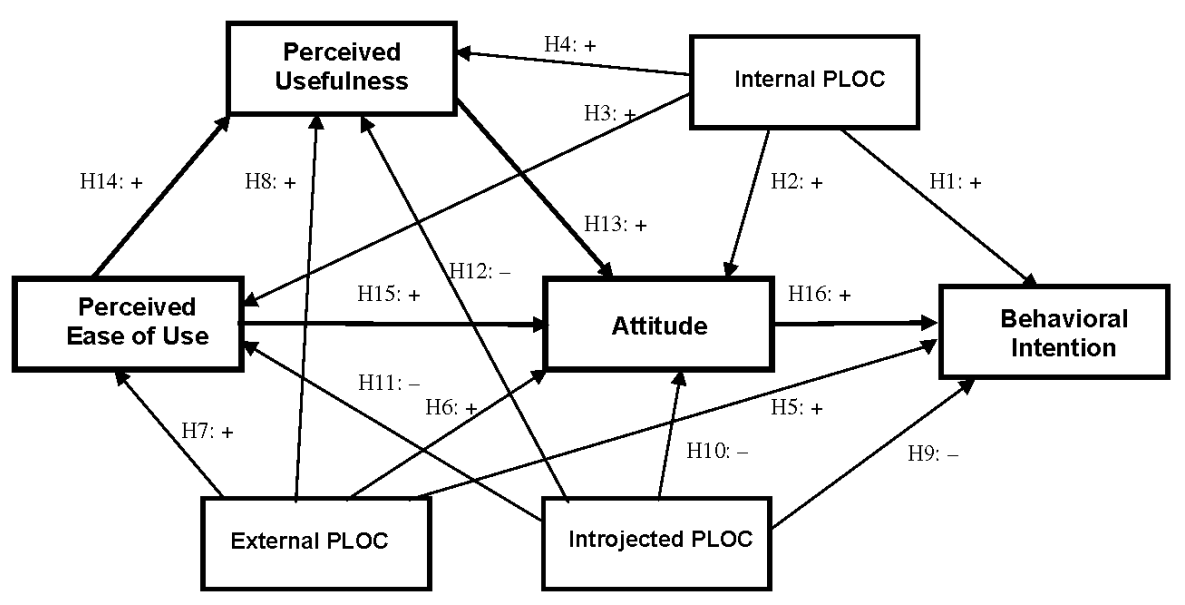

Figure 1. Theoretical Model

feelings of autonomy and external pressure and how they may have a cumulative influence on behavior.

Figure 1 depicts our research model, which depicts how endogenous motivations influence user intentions. There is sparse systematic theoretical or practical guidance about how managers could enhance adoption and use by influencing user perceptions beyond performance expectancy [4]. Hence, based on such recent recommendations in IS research, we modeled endogenous motivations as antecedents of key user beliefs of perceived usefulness and ease of use. ${ }^{3}$

\section{Internal, External, and Introjected PLOC}

Figure 2 depicts different types of endogenous motivations and how they relate to specific PLOC types. The following sections explain the PLOC-motivation relationships in detail, supporting the development of hypotheses based on the model.

\section{Internal PLOC}

Identified PLOC and intrinsic PLOC are associated with feelings of volition where actors perceive themselves as the "origin" of their behavior: both types represent different types of internal PLOC (IPLOC). Intrinsic PLOC (INTPLOC) is based on what comes instinctively and spontaneously [26]. Such spontaneous behavior is typically characterized by self-perceived reasons for behavior performed simply for inherent enjoyment or fun [46].

Identified PLOC (IDPLOC), in contrast, represents users' actions based on personal values and meaningful goals and outcomes [26]. It is characterized by feelings of autonomy and associated behavior is performed freely [26]. As it results from internalization and integration of external regulations adopted by individuals as personally important or valuable, it is a type of extrinsic motivation. Although still extrinsic in 


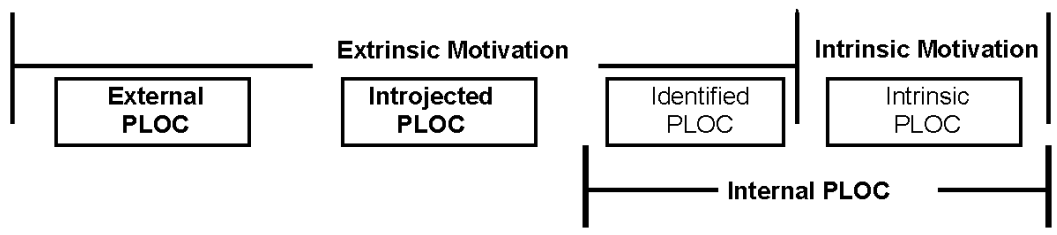

Figure 2. Endogenous Motivations

nature, identified regulation is relatively volitional and, in this sense, approximates intrinsic motivation, so these two types of motivation are sometimes combined into a composite of autonomous motivation $[8,58,59]$. However, unlike the dichotomy of extrinsic-intrinsic motivations, identified PLOC is not dependent upon external rewards or "referent others" but is focused on regulations, values, and outcomes. OIT can therefore explain why some social values are accepted by users while others are not. Interestingly, IS research is rather silent on this important issue [19, 35, 62].

Consistently, internal PLOC, which denotes feelings of experienced volition, is used to characterize both identified PLOC and intrinsic PLOC [23, 37]. As far as experience of self-endorsed choice and volition is concerned, both denote an internal PLOC; however, only identified PLOC can be managerially influenced.

Advancing beyond the extrinsic-intrinsic dichotomy, OIT proposes that extrinsic motivation can vary greatly in the extent to which it is volitional [48]. For example, adoption or use of a system because of fear of managerial sanctions is extrinsically motivated and based on feelings of coercion. When one chooses to adopt or use the same system for personally meaningful goals (e.g., to achieve a performance goal), the behavior is still extrinsically motivated. However, in this case, it is based on feelings of volition. Such subjective instrumental concerns may include personal or professional growth or advancement. In both cases, whether out of fear of sanctions or achievement of a goal, behavior is not based on inherent personal interest. Both cases represent intentional behavior; however, their relative autonomy varies [48]. The former is based on external pressures, while the latter is based on self-endorsed choice, representing the case of volitional extrinsic motivation, a concept sparsely examined in prior research. The effect of volitional extrinsic motivation on intentions is similar to that of intrinsic motivation associated with spontaneous performance of the specific behavior [23]. Given the role of internal PLOC in positively influencing users' behavioral intentions $(B I)$, we hypothesize that:

\section{Hypothesis 1: Internal PLOC will be positively related to users' intentions.}

Attitude $(A)$ is defined as the user's positive or negative feelings (evaluative affect) about performing the specific behavior [29]; a function of one's feeling that system adoption and use is experienced as positive (desirable) or negative (undesirable). Positive feelings of autonomy, volition, and freedom are expected to be associated with a positive attitude and desirability of the behavior. When motivated by internal drives of self-development and self-growth in executing a specific behavior, one tends to associate such behavior with positive feelings. Initial adoption and experienced 
use behavior when characterized by perceived autonomy are expected to positively influence attitude [34]. Users who feel that doing what they are doing is personally important and feel good about themselves while doing so will have a positive attitude [15]. Hence,

Hypothesis 2: Internal PLOC will be positively related to users' attitudes.

The developmental focus of the endogenous theory broadens perceived ease of use $(P E O U)$ to include affective psychological feelings. Internal PLOC is associated with perceptions of volition and autonomy. The resulting behavior is perceived as relatively effortless and easy. In contrast, when one feels coerced to adopt and execute a given behavior, the related psychological feelings can be as enervating as bearing a physical burden $[14,33]$. Even activities such as assembly line work, typically considered as repetitive, routine, and monotonous, can be felt to be an enjoyable and challenging "game," in spite of great physical effort [14]. Hence,

Hypothesis 3: Internal PLOC will be positively related to perceived ease of use.

Internal PLOC broadens our view of performance beyond satisfying external instrumental contingencies to seeking self-development, growth, and fulfillment. In a learning context, a person might seek high grades primarily for others' approval. In a work-related context, a person might seek a supervisor's approval. Prior research has typically taken a normative view of self-perceived performance, productivity, and effectiveness in required or mandated activities. However, that is only a partial view of perceived usefulness $(P U)$. Individuals may often also perceive performance, productivity, and effectiveness in terms of what they deem as personally meaningful or contributing to personal development and growth [55]. Hence, in the developmental focus of OIT, individuals could consider an act as useful if it includes personally meaningful activities and affords development and growth [23, 24, 25]. For example, winning athletic teams and individuals are often coached to enjoy and have fun in their performance (how well they play) rather than being obsessed by the scoreboard (what they score) [14]. Research on flow consistently suggests that those having an internal PLOC tend to not only perceive what they are doing as useful but also perform better [45]. Hence,

Hypothesis 4: Internal PLOC will be positively related to perceived usefulness.

\section{External PLOC}

From the endogenous perspective, the important developmental problem involves advancing beyond external regulation to self-regulation in the absence of immediate external consequences [23]. External PLOC (EPLOC), corresponding to external regulation of behavior, often represents an important intermediate step through which social influences are internalized and integrated. As shown in Figure 2, external PLOC represents extrinsic motivation in its most basic form and is based on attainment of 
immediate consequences administered by others [23]. It is associated with perceived reasons for one's behavior that is attributed to external authority or compliance [46]. This assumes that there is no conflict between perceived external influences and personal values of the user.

External PLOC represents the least autonomous form of extrinsic motivation. Externally regulated behaviors are typically performed to satisfy an external demand and might make users feel controlled or alienated [20,48]. As user intentions are contingent upon external factors, they tend to be less sustainable if those contingencies cease or become less relevant. Hence, external PLOC is characterized by a positive but perhaps weak influence on intentions. Therefore,

Hypothesis 5: External PLOC will be positively related to users' intentions.

Social rewards and contingencies such as praise, approval, and social esteem may motivate external regulation and "promote certain otherwise non-spontaneous behaviors" [23, p. 135]. Under the influence of external PLOC, a user may attribute his or her evaluative feelings about performing the specific behavior to such external influences. Given that positive feelings associated with autonomy and choice are less prominent, external PLOC will have a perhaps weak influence on user attitudes. Hence,

\section{Hypothesis 6: External PLOC will be positively related to users' attitudes.}

In contrast to personally meaningful and self-growth-oriented activities (characterized by internal PLOC), pursuit of less meaningful activities (characterized by external PLOC) is associated with lesser feelings of ease [16, 51]. The excitement and enthusiasm associated with internal PLOC would typically be lacking for activities that are not fully self-endorsed [25], such as when users perform a computer-based activity they do not find adequately interesting. They may not be as enthusiastic in performing that activity; however, they may still perform it given a reasonable external incentive or reward. Absent personally meaningful external influences (such as incentives or rewards), execution of a specific behavior may be perceived as coerced and pressured. However, given a personally meaningful incentive, the same behavior may be perceived as less burdensome, more autonomous, and relatively easy to perform [23]. ${ }^{4}$

Hypothesis 7: External PLOC will be positively related to perceived ease of use.

IS researchers have recently recommended "opening the black box of usefulness" to understand what exactly makes a specific technology perceived as being useful [4]. OIT provides a window into the black box. While some may perceive usefulness in the instrumentality of job performance, others may perceive it in the learning, growth, and development of the self. The latter aspects are the key focus of OIT and are finding increased interest among IS researchers studying IT adoption and use [3, 4, 52]. IT managers in industry realize that users may respond positively to both incentives of development and growth of valuable skills as well as to monetary incentives. External influences and incentives may be perceived as personally meaningful and useful when they are not deemed as coercive [23]. ${ }^{5}$ Hence, 
Hypothesis 8: External PLOC will be positively related to perceived usefulness.

Introjected PLOC

Until now we focused on scenarios where there is negligible conflict between perceived external behavioral influences and personal norms and values. Next, we focus on situations where there is an apparent conflict. This psychological condition, called the "introjected" state, has received little attention in prior research (except for one recent study [44]). However, it can help develop new understanding about situations of ambivalence where a user is torn between social norms and personal values.

The conflict in introjected PLOC (IJPLOC) is theorized to be caused by misalignment of perceived social influences and personal values. Such extrinsic motivation spawns perceived reasons for one's behavior that are related to affective feelings of guilt and shame, and esteem-based pressures to act [26, 46]. Introjected PLOC is often associated with strong self-imposed feelings of coercion that might lead to rejection of the "imposed" behavior. Although both external PLOC and introjected PLOC are primarily associated with feelings of external pressure, they represent distinct psychological states with different behavioral outcomes [46]. While external PLOC is characterized by relatively negligible resistance resulting in compliance, introjected PLOC involves strong violation of personal values. The strong feelings of compulsion, compliance, and tension may be self-administered even in the absence of any external pressures.

With its partially ingested regulation that is not internalized as one's own, introjected regulation implies that integration of the internalized social values in an individual's value system has failed. Feelings of pressure, tension, ambivalence, anxiety, and frustration associated with ego involvement result in diminished performance [47]. Introjection is associated with a negative correlation between self-valuation of associated tasks as well as self-perceived autonomy and behavioral intentions [27]. If users perceive personal disincentives in using a system prescribed by social norms, they may simply choose to reject it. Hence, the introjected state will be characterized by a negative influence on intentions. Hence,

\section{Hypothesis 9: Introjected PLOC will be negatively related to users' intentions.}

When users find themselves conflicted in doing what they perceive as mandated by social norms, unpleasant evaluative feelings may result. For example, commissionbased salespersons who use the system for configuring and selling products would be motivated by sales of the products. They may find themselves conflicted when they feel coerced to do activities (such as documentation or knowledge sharing) that may not directly contribute to their sales commission. Hence, while proactively documenting customer feedback and sharing knowledge about products may be important for the design of innovative and competitive products, it may be peripheral to their "motive." The greater the conflict between personally meaningful goals and those they feel coerced into adopting, the more intense are the negative evaluative feelings (attitude) toward the specific behaviors [15]. Hence, 
Hypothesis 10: Introjected PLOC will be negatively related to users'attitudes.

In prior behavioral research, introjected regulation has been found to be positively related to perceptions about expending more effort [46]. Similarly, in system adoption and use, introjected regulation is expected to result in perceptions about expending greater effort and thereby lessening perceived ease of use. In a situation of introjected regulation, one is in a self-conflicted state, as external values are partially internalized and result in self-induced feelings of compulsion. As one feels pressured by guilt and shame to execute a behavior, such feelings tend to have a negative influence on perceived ease of use. These observations are consistent with prior findings about introjected regulation [34]. Thus,

Hypothesis 11: Introjected PLOC will be negatively related to perceived ease of use.

Social norms may mandate use of systems for purposes that are not necessarily congruent with personal values, where both instrumental and developmental beliefs about perceived usefulness are missing. For example, users may perceive a system as having neither personal meaningfulness in terms of self-development (i.e., usefulness of one type) nor any other merit in complying with external influences (i.e., usefulness of another type). In particular, when personal values collide with users' perceptions about external influences and related norms, negative perceptions about usefulness may be particularly strong. As introjected PLOC is characterized by feelings of pressures to perform, poorer coping with failures, and performance anxiety, it is expected to have a negative effect on perceived usefulness [23]. Hence, it follows that

Hypothesis 12: Introjected PLOC will be negatively related to users' perceived usefulness.

In the context of OIT, our focus is on how users understand and describe their own reasons for acting, and the relations of such reasons to self-perceived feelings of autonomy [46]. Our focus on directly understanding and assessing users' experienced volition has important implications for advancing research on system user motivations. As Davis noted, the user "may want to do what Referent X thinks he/she should do, not because of X's influence, but because the act is consistent with the subject's own attitude" [18, p. 228]. The theoretical framework proposed in this paper helps clearly discern if the user's behavior results from perceived volition (in the case of internal PLOC), perceived external influences (in the case of external PLOC), or some combination of both. Our framework also helps recognize the case of the ambivalent user resulting from the conflict between perceived volition and perceived external influences (in the case of introjected PLOC).

\section{TAM Constructs and Relationships}

In Figure 1, prior constructs and relationships adopted from TAM (technology acceptance model) are shown and are briefly explained here. Based on belief-attitude- 
behavior models of the theory of reasoned action [1], Davis et al. [18] suggested that technology use intentions are predicted by perceived usefulness and perceived ease of use. Perceived ease of use is posited to influence behavioral intentions through two causal pathways: an indirect effect through perceived usefulness as well as indirect effect through attitude. Perceived usefulness is posited to influence behavioral intentions through attitude. Hence,

Hypothesis 13: Perceived usefulness will be positively related to users' attitudes.

Hypothesis 14: Perceived ease of use will be positively related to perceived usefulness.

Hypothesis 15: Perceived ease of use will be positively related to users' attitudes.

Hypothesis 16: System users' attitude will be positively related to users' intentions.

\section{Methodology}

WE EXAMINED A POPULAR WEB-BASED EDUCATION PLATFORM, Blackboard, at a private university in the northeastern United States. The IT adoption and use context was the required introductory core IS course. Conducted over 15 weeks and meeting twice a week, the course enrolled seniors, juniors, sophomores, and freshmen. Both genders were equally represented and approximately half had prior work experience.

The system provided users with access to course syllabi, announcements and guidelines, lecture notes, multimedia simulations, related Web resources, exercises and assignments, and student grades. Moreover, it provided communication and collaboration capabilities, including class and group discussion boards, group file sharing, and chat sessions. Paper-based printouts of the necessary materials were provided for corresponding electronic versions that were typically posted in advance. Most graded homework assignments, class work assignments, and team projects were required to be submitted electronically through the system's digital drop box. While some features necessitated use (such as download of data files, electronic submission of assignments and projects, and grades scored on completed deliverables), others were optional (such as electronic group collaboration). There were no explicit rewards or penalties specified for more or less use of the system or any of its capabilities. System usage statistics broadly distinguished use and nonuse, but did not provide specifics on quantity or quality of use. Users were also free to use any and all alternative systems-such as phone, face-to-face meetings, other e-mail systems-for communication and collaboration besides Blackboard.

A one-page outline of key system capabilities was provided to users in the first week of class. The first set of instruments was administered the following week. Users were told to write a unique code derived from personal identifiers on the cover of the com- 
pleted survey instrument. The code was self-reported and self-derived from identifiers known only to the respective respondents, hence their anonymity was ensured. ${ }^{6}$

Students subsequently used the system for course-related activities. At the midterm, an instrumental check was administered by displaying usage statistics that revealed the extent to which students used the system. In the fifteenth week, the second set of instruments was administered. From survey data collected for 211 users, 189 usable responses for the initial adoption stage (second week) and 181 usable responses for the experienced use stage (fifteenth week) were received. ${ }^{7}$ The key motive for analyzing "experienced use" data was to further understanding about internalization of specific behaviors as recommended by recent IS research [3, 52].

\section{Operationalization of Variables}

Despite the required nature of the course and limited necessity for using the system, most specific activities were not mandated. Hence, user volition was anticipated to play an important role in initial adoption and experienced use for most system activities. Given the mixed volitional-and-necessary system use typical of many new technologies, direct measurement of users' experienced volition is therefore necessary to know if use resulted from perceived feelings of choice, pressure, or ambivalence. Such measures are also necessary to precisely distinguish between distinct motivations underlying users' initial adoption and experienced use.

Standard procedures for questionnaire construction, measurement items, data collection, and validation of relationships were used [12, 28]. As detailed in the Appendix, all variables were measured using multi-item seven-point Likert scales.

Given our focus on the individual level of analysis, all scales were operationalized at the same level. Measures of perceived usefulness, attitude, and behavioral intentions were adopted from prior studies [17, 18, 60].

Endogenous motivation measures proposed by Ryan and Connell [46] and recommended by Deci and Ryan [25] for OIT research were used. These measures were adapted for the context of IT adoption and use. External PLOC was assessed using self-perceived reasons that explain behavior by referencing external pressures. Introjected PLOC was assessed using self-perceived reasons for behavior in terms of ambivalence between social norms and personal values. Internal PLOC was assessed using reasons that reflected self-determined choice and volition. ${ }^{8}$ Consistent with Ryan and Connell [46], subjects were asked to endorse these reasons to the extent they explained their own behavior. Individual items used for measuring the respective endogenous motivations (latent variables) are reflective in nature.

\section{Results}

WE USED AMOS VERSION 5.0.1, a structural equation modeling application, to estimate the measurement models and the structural models using full information maximum likelihood estimation. 


\section{Testing for Common Method Bias}

To minimize common method bias, procedural and statistical remedies recommended by Podsakoff et al. [43] were applied, including proximal and methodological separation of measurement. Respondents were assured of anonymity and there was no incentive or disincentive in order to minimize evaluation apprehension. Psychological separation was achieved by using a cover story before administration of the instrument. The measurement items for various predictor and criterion variables were intermixed in a random fashion to further minimize consistency bias. Harman's one-factor test [43] confirmed that no general factor was apparent in the unrotated factor solution indicating that common method variance was not a problem.

\section{Confirmatory Factor Analysis and Measurement Models}

As a precursor to the assessment of the hypothesized structural model, we needed to ensure that the measurement model was operating adequately. Following the recommended two-stage analytical procedures [2], confirmatory factor analysis (CFA) was first conducted to assess the measurement model. CFA was chosen because our research model is highly theory based and we are confirming the application of an established theory, OIT. CFA was also chosen given its superiority for establishing the convergent and discriminant validity of the constructs in our model compared with an exploratory factor analysis. For purposes of CFA, all measured items were modeled as reflective indicators of their corresponding latent constructs, all constructs were allowed to covary freely in the measurement model, and each factor loading and interconstruct correlation was scrutinized individually. ${ }^{9}$

Goodness-of-fit criteria used for fitting the measurement models included comparative fit index (CFI) [5, 6], Tucker-Lewis index (TLI) [56], and root mean square error of approximation (RMSEA) [9, 38]. The fit indices of the measurement model for adoption $\left(\chi^{2} / \mathrm{df}\right.$ [degrees of freedom] $\left.=1.88, \mathrm{CFI}=0.92, \mathrm{TLI}=0.91, \mathrm{RMSEA}=0.06\right)$ and use $\left(\chi^{2} / \mathrm{df}=2.21, \mathrm{CFI}=0.90, \mathrm{TLI}=0.90, \mathrm{RMSEA}=0.08\right)$ indicated acceptable fit of the model to the data given acceptable cutoff values of $\chi^{2} / \mathrm{df}$ less than 3 [36], and fit statistics approaching or exceeding 0.90 for CFI [6], 0.90 for TLI [36], and RMSEA between 0.05 and 0.08 [9].

To validate our measurement model, we assessed content, convergent, and discriminant validity. Content validity was established by ensuring consistency between the measurement items and the extant literature. This was done by following the process of scale development previously described and pilot testing the instrument. In addition, senior researchers and practitioners well versed in research methods reviewed and commented on the instrument under development. Scale reliability was assessed using two methods. Composite reliability and coefficient Cronbach [13] alpha scores were used as measures of reliability. Similar to alpha scores, composite reliabilities reflect the internal consistency of the scale items measuring a given factor $[30,31,32$, 42]. Both composite reliability and alpha scores exceeded the recommended cutoff value of 0.70 for adoption and use as shown in the Appendix and Table 2. 
Table 2. Confirmatory Factor Analysis

\begin{tabular}{lccc} 
Measures & Items & $\begin{array}{c}\text { Composite } \\
\text { reliability }\end{array}$ & $\begin{array}{c}\text { Average } \\
\text { variance } \\
\text { extracted }\end{array}$ \\
\hline Panel a: Initial adoption & & & \\
\hline Attitude & 2 & 0.85 & 0.75 \\
Behavioral intention & 3 & 0.88 & 0.72 \\
External PLOC & 3 & 0.87 & 0.69 \\
Internal PLOC & 4 & 0.89 & 0.67 \\
Introjected PLOC & 7 & 0.94 & 0.67 \\
Perceived ease of use & 6 & 0.93 & 0.69 \\
Perceived usefulness & 5 & 0.93 & 0.73 \\
Panel b: Experienced use & & & \\
\hline Attitude & & & \\
Behavioral intention & 2 & 0.82 & 0.69 \\
External PLOC & 3 & 0.85 & 0.65 \\
Internal PLOC & 3 & 0.85 & 0.66 \\
Introjected PLOC & 4 & 0.86 & 0.60 \\
Perceived ease of use & 7 & 0.93 & 0.67 \\
Perceived usefulness & 6 & 0.92 & 0.65 \\
\hline
\end{tabular}

Convergent validity was assessed by examining the average variance extracted for all measures and scale item loadings. As shown in Table 2, average variances extracted met the cutoff criteria of 0.5 for adoption and use [30, 31]. Convergent validity was also demonstrated when all scale items loaded significantly on their hypothesized latent constructs [2] for adoption and use as shown in Table 3. All scale items met the loading value cutoff of 0.70 on respective scales for inclusion in our model. Table 3 also lists the standard errors and critical ratios for all scale items.

Finally, discriminant validity was assessed by computing the square root of the average variance extracted as recommended by Fornell and Larcker [30, 31]. The results in Table 4 confirm discriminant validity: the square root of the average variance extracted for each construct is greater than the levels of the correlations involving the construct. Besides interitem correlations, Table 4 also provides means and standard deviations.

\section{Structural Models}

Having found an acceptable measurement model, the hypothesized structural path relationships were then examined. To test our hypotheses, we specified the following structural equations in a simultaneous equation model for any specific time $t$ : 
Table 3. Measurement Model

\begin{tabular}{|c|c|c|c|}
\hline Indicator variables & $\begin{array}{l}\text { Standard } \\
\text { error }\end{array}$ & $\begin{array}{l}\text { Critical } \\
\text { ratio }\end{array}$ & Loadings \\
\hline \multicolumn{4}{|c|}{ Panel a: Initial adoption } \\
\hline \multicolumn{4}{|l|}{ Attitude } \\
\hline A1 & fixed & & 0.772 \\
\hline A2 & 0.111 & 10.100 & 0.946 \\
\hline \multicolumn{4}{|l|}{ Behavioral intention } \\
\hline $\mathrm{Bl} 1$ & fixed & & 0.877 \\
\hline $\mathrm{BI} 2$ & 0.069 & 12.801 & 0.775 \\
\hline $\mathrm{BI} 3$ & 0.065 & 15.600 & 0.887 \\
\hline \multicolumn{4}{|l|}{ External PLOC } \\
\hline EXPLOC1 & fixed & & 0.876 \\
\hline EXPLOC2 & 0.070 & 12.231 & 0.802 \\
\hline EXPLOC3 & 0.072 & 12.308 & 0.806 \\
\hline \multicolumn{4}{|l|}{ Internal PLOC } \\
\hline IDPLOC1 & fixed & & 0.748 \\
\hline IDPLOC2 & 0.085 & 11.711 & 0.840 \\
\hline INTPLOC1 & 0.080 & 12.087 & 0.865 \\
\hline INTPLOC2 & 0.087 & 11.326 & 0.815 \\
\hline \multicolumn{4}{|l|}{ Introjected PLOC } \\
\hline IJPLOC1 & fixed & & 0.885 \\
\hline IJPLOC2 & 0.071 & 12.149 & 0.725 \\
\hline IJPLOC3 & 0.063 & 15.793 & 0.842 \\
\hline IJPLOC4 & 0.057 & 15.886 & 0.845 \\
\hline IJPLOC5 & 0.056 & 15.306 & 0.829 \\
\hline IJPLOC6 & 0.061 & 14.928 & 0.818 \\
\hline IJPLOC7 & 0.056 & 14.189 & 0.796 \\
\hline \multicolumn{4}{|l|}{ Perceived ease of use } \\
\hline PEOU1 & fixed & & 0.818 \\
\hline PEOU2 & 0.087 & 12.013 & 0.765 \\
\hline PEOU3 & 0.085 & 13.611 & 0.833 \\
\hline PEOU4 & 0.083 & 12.133 & 0.769 \\
\hline PEOU5 & 0.073 & 15.466 & 0.905 \\
\hline PEOU6 & 0.072 & 15.217 & 0.896 \\
\hline \multicolumn{4}{|l|}{ Perceived usefulness } \\
\hline PU1 & fixed & & 0.832 \\
\hline PU2 & 0.073 & 13.892 & 0.830 \\
\hline PU3 & 0.067 & 15.325 & 0.882 \\
\hline PU4 & 0.065 & 16.276 & 0.916 \\
\hline PU5 & 0.071 & 13.222 & 0.805 \\
\hline
\end{tabular}


Table 3. Continued

\begin{tabular}{|c|c|c|c|}
\hline Indicator variables & $\begin{array}{c}\text { Standard } \\
\text { error }\end{array}$ & $\begin{array}{l}\text { Critical } \\
\text { ratio }\end{array}$ & Loadings \\
\hline \multicolumn{4}{|c|}{ Panel b: Experienced use } \\
\hline \multicolumn{4}{|l|}{ Attitude } \\
\hline A1 & & & 0.817 \\
\hline A2 & 0.122 & 9.141 & 0.848 \\
\hline \multicolumn{4}{|l|}{ Behavioral intention } \\
\hline $\mathrm{Bl} 1$ & fixed & & 0.804 \\
\hline $\mathrm{BI} 2$ & 0.098 & 10.180 & 0.733 \\
\hline $\mathrm{BI} 3$ & 0.091 & 12.011 & 0.869 \\
\hline \multicolumn{4}{|l|}{ External PLOC } \\
\hline EXPLOC1 & fixed & & 0.875 \\
\hline EXPLOC2 & 0.070 & 9.246 & 0.712 \\
\hline EXPLOC3 & 0.085 & 13.014 & 0.890 \\
\hline \multicolumn{4}{|l|}{ Internal PLOC } \\
\hline IDPLOC1 & fixed & & 0.708 \\
\hline IDPLOC2 & 0.096 & 9.820 & 0.778 \\
\hline INTPLOC1 & 0.099 & 10.480 & 0.834 \\
\hline INTPLOC2 & 0.104 & 9.910 & 0.786 \\
\hline \multicolumn{4}{|l|}{ Introjected PLOC } \\
\hline IJPLOC1 & fixed & & 0.905 \\
\hline IJPLOC2 & 0.064 & 14.598 & 0.797 \\
\hline IJPLOC3 & 0.058 & 16.842 & 0.853 \\
\hline IJPLOC4 & 0.052 & 18.585 & 0.890 \\
\hline IJPLOC5 & 0.063 & 14.024 & 0.780 \\
\hline IJPLOC6 & 0.055 & 18.547 & 0.889 \\
\hline IJPLOC7 & 0.061 & 14.556 & 0.796 \\
\hline \multicolumn{4}{|c|}{ Perceived ease of use } \\
\hline PEOU1 & fixed & & 0.813 \\
\hline PEOU2 & 0.082 & 13.392 & 0.851 \\
\hline PEOU3 & 0.100 & 9.586 & 0.693 \\
\hline PEOU4 & 0.090 & 11.554 & 0.767 \\
\hline PEOU5 & 0.084 & 13.926 & 0.874 \\
\hline PEOU6 & 0.083 & 13.083 & 0.837 \\
\hline \multicolumn{4}{|l|}{ Perceived usefulness } \\
\hline PU1 & fixed & & 0.893 \\
\hline PU2 & 0.060 & 14.287 & 0.798 \\
\hline PU3 & 0.054 & 20.041 & 0.932 \\
\hline PU4 & 0.059 & 18.051 & 0.892 \\
\hline PU5 & 0.059 & 16.439 & 0.856 \\
\hline
\end{tabular}




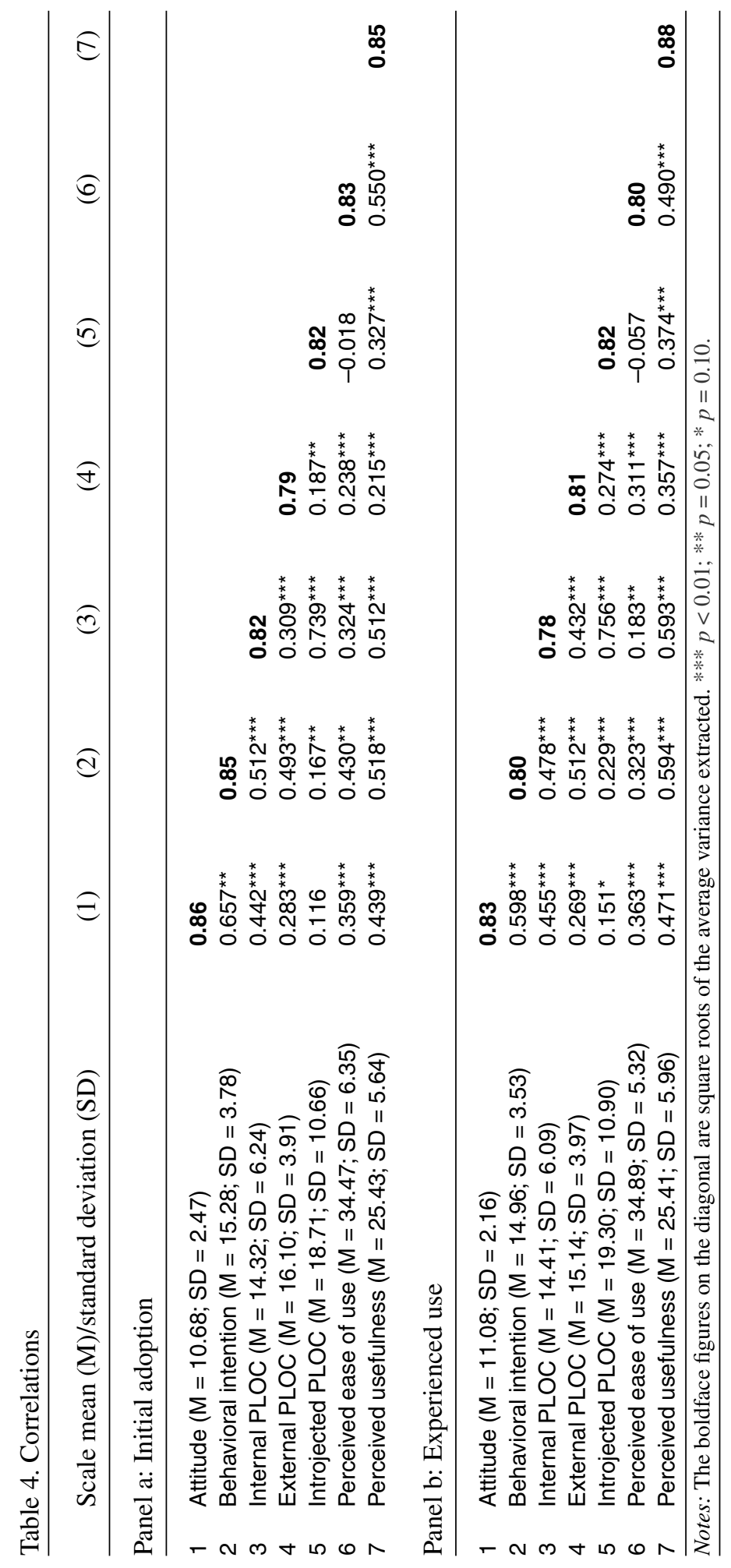




$$
\begin{aligned}
& A_{t}=\alpha_{o}+\alpha_{1} * I P L O C_{t}+\alpha_{2} * E^{2} P L O C_{t}+\alpha_{3} * I J P L O C_{t}+ \\
& \alpha_{4} * P U_{t}+\alpha_{5} * P E O U_{t}+\varepsilon_{1} \\
& B I_{t}=\beta_{o}+\beta_{1} * I_{L L O C}+\beta_{2} * E P L O C_{t}+\beta_{3} * I I_{L L O C}+\beta_{4} * A_{t}+\varepsilon_{2}
\end{aligned}
$$

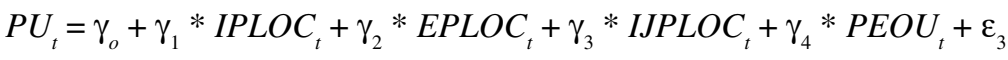

$$
\begin{aligned}
& \text { PEOU }_{t}=\eta_{o}+\eta_{1} * \text { IPLOC }_{t}+\eta_{2} * \text { EPLOC }_{t}+\eta_{3} * \text { IJPLOC }_{t}+\varepsilon_{4} .
\end{aligned}
$$

The evaluation of model fit was based on the parameter estimates, appropriateness of standard errors, and statistical significance of parameter estimates [10]. The fit indices of the structural model for adoption $\left(\chi^{2} / \mathrm{df}=1.89, \mathrm{CFI}=0.92, \mathrm{TLI}=0.90, \mathrm{RMSEA}=\right.$ $0.06)$ and use $\left(\chi^{2} / \mathrm{df}=2.24, \mathrm{CFI}=0.89, \mathrm{TLI}=0.89\right.$, RMSEA $\left.=0.08\right)$ indicated acceptable fit of the model to the data given acceptable cutoff values around 0.90 for CFI [6], 0.90 for TLI [36], and RMSEA between 0.05 and 0.08 [9]. The fit indices need to be examined while considering the predictive power of the model as determined by factor loadings and standardized paths [11]. Based on an examination of the fit indices and predictive power, both adoption and use models fit the data well.

Figure 3 summarizes the estimated standardized path coefficients for the adoption model and Figure 4 does the same for the use model. Table 5 summarizes the comparative results of all hypotheses tested for initial adoption of the system and its experienced use.

$\mathrm{H} 1$ through $\mathrm{H} 4$, representing all predicted relationships of internal PLOC, are supported for both adoption and use. For external PLOC, H5 and H7 (for intentions and ease of use, respectively) are supported for both adoption and use, and $\mathrm{H} 6$ and $\mathrm{H} 8$ (for attitude and usefulness, respectively) are not supported. For introjected PLOC, H10 and $\mathrm{H} 11$ (for attitude and ease of use, respectively) are supported for both adoption and use, $\mathrm{H} 9$ (for intentions) is supported only for adoption, and H12 (for usefulness) is not supported. For other relationships, $\mathrm{H} 14$ and $\mathrm{H} 16$ are supported for both adoption and use, H13 is supported only for adoption, and H15 is not supported.

The analysis of the structural models shows that our research model explains 61 percent of the variance in user intentions on initial adoption and 53 percent of the variance on experienced use. In addition, our model explains 44 percent of the variance in perceived usefulness on initial adoption and 52 percent of the variance on experienced use.

\section{Direct and Indirect Effects}

Perceived ease of use and usefulness are recognized as key user beliefs in prior IT adoption and use research. In our models, users' perceptions about volition (or lack thereof) in system use are depicted as key determinants of user intentions as well as user beliefs. Hence, to know the relative strength of relationships and relative contributions to prediction and explanation of user intentions, an analysis of direct and indirect effects was performed (see Table 6).

Perceived ease of use is determined completely by direct effects of internal PLOC, introjected PLOC, and external PLOC for both adoption $(0.713,-0.572$, and 0.130, 


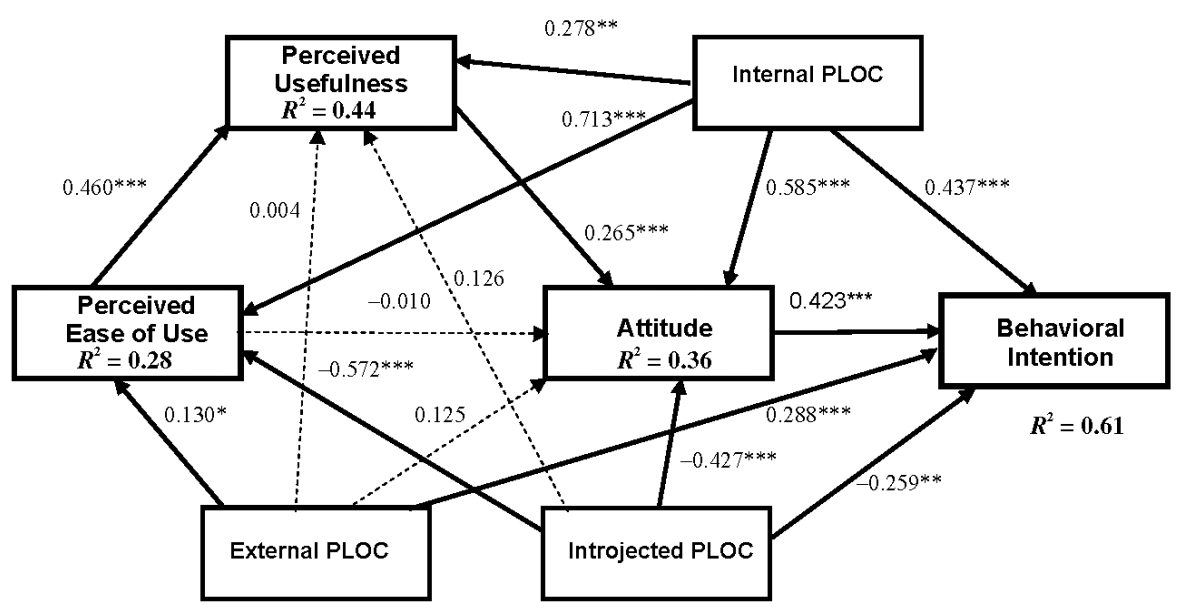

Figure 3. Model Results: Standardized Path Coefficients: Initial Adoption

Notes: Solid arrows show significant paths, dashed arrows show nonsignificant paths. $* * * p<0.01 ; * * p<0.05 ; * p<0.10$.

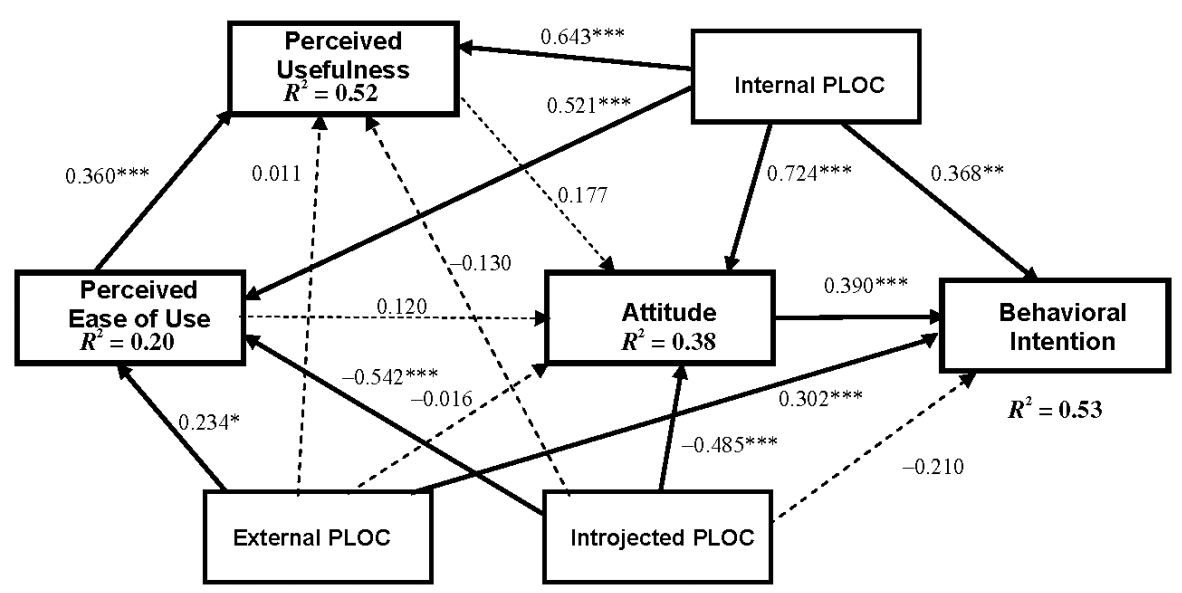

Figure 4. Model Results: Standardized Path Coefficients: Experienced Use

Notes: Solid arrows show significant paths, dashed arrows show nonsignificant paths.

$* * * p<0.01 ; * * p<0.05 ; * p<0.10$.

respectively) and use $(0.521,-0.542$, and 0.234 , respectively). While internal PLOC has a strong positive influence and external PLOC a lesser positive influence, introjected PLOC exerts a strong negative influence on perceived ease of use. For adoption as well as use, perceived usefulness is determined primarily by direct effect of perceived ease of use ( 0.460 for adoption and 0.360 for use) and both direct and indirect effects of internal PLOC. In both cases, internal PLOC exerts a strong direct effect $(0.278$ for adoption and 0.643 for use) in addition to an indirect effect ( 0.328 for adoption and 0.188 for use) mediated by perceived ease of use. 


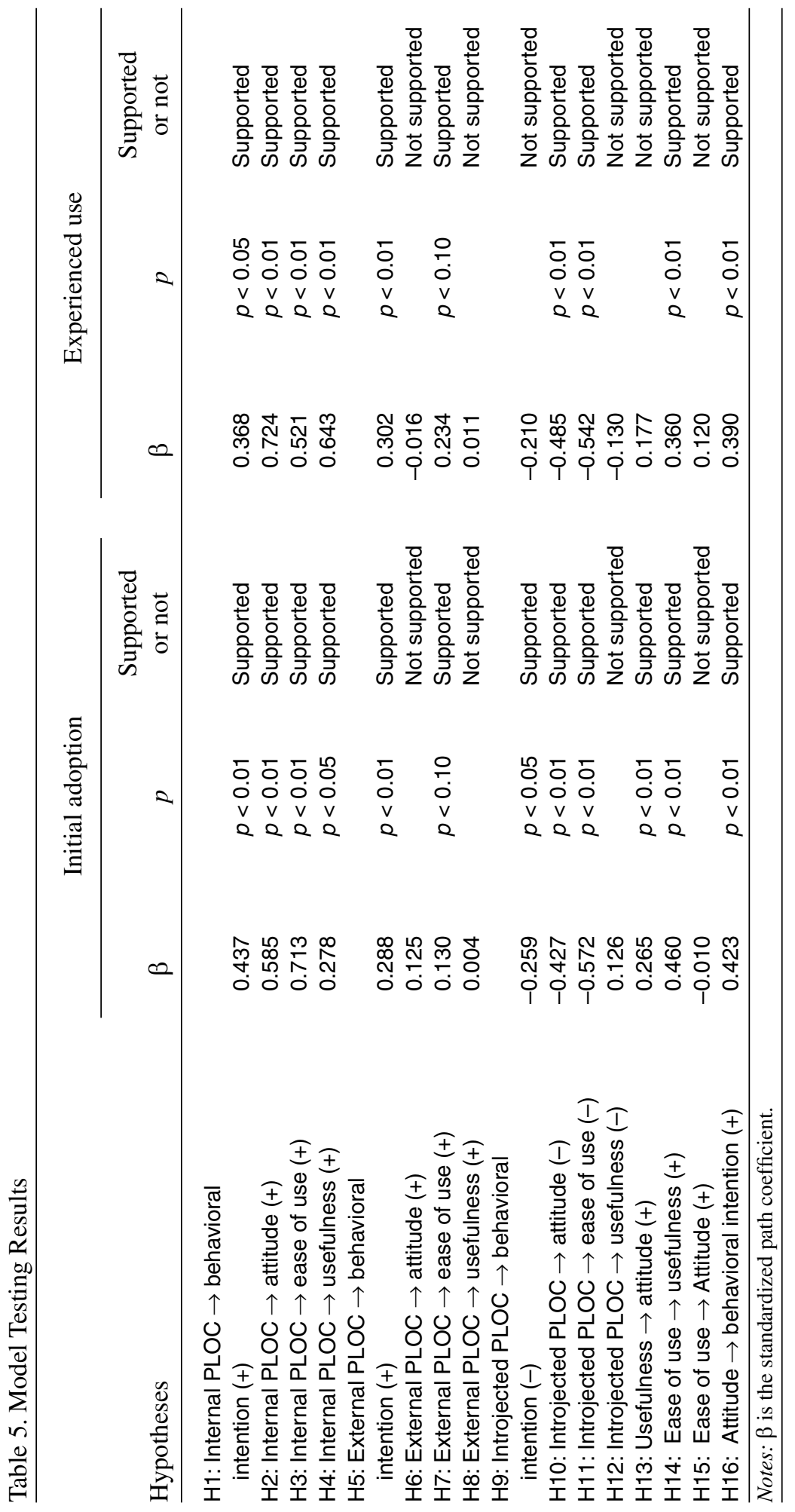




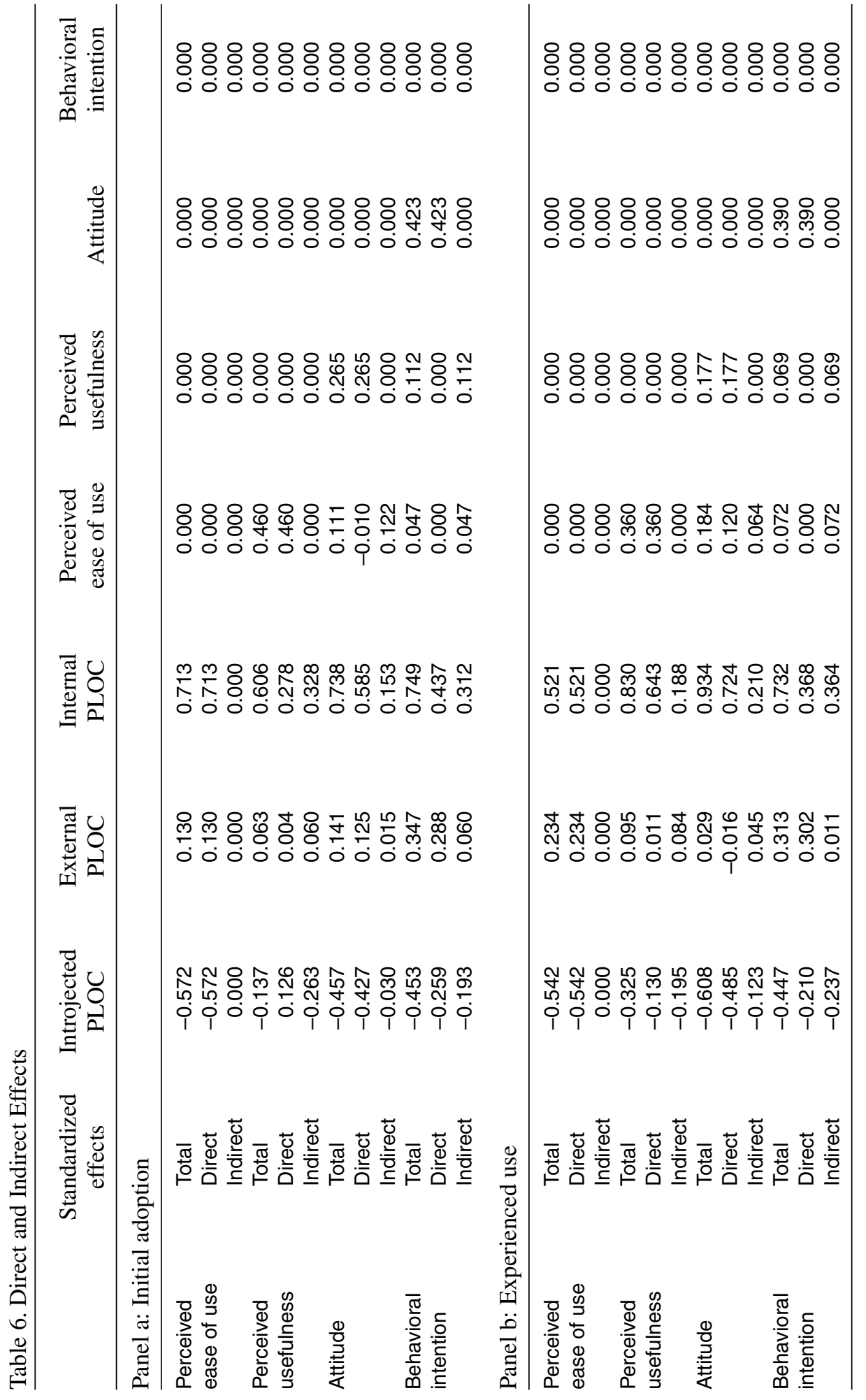


Attitude is predominantly affected positively by internal PLOC for both adoption (direct effect: 0.585; indirect effect: 0.153) and use (direct effect: 0.724). Internal PLOC affects attitude indirectly through perceived usefulness at the time of adoption. Attitude is also affected negatively by introjected PLOC on adoption and use ( -0.427 for adoption and -0.485 for use). Behavioral intention is positively associated with internal PLOC at the time of both adoption (direct effect: 0.437 ; indirect effect: 0.312 ) and use (direct effect: 0.368 ; indirect effect: 0.364 ). The key negative influence on behavioral intention is that of introjected PLOC for both adoption (direct effect: -0.259 ; indirect effect: -0.193 ) and use (indirect effect: -0.237 ). Introjected PLOC affects behavioral intention indirectly through attitude at the time of use. A somewhat lesser influence on behavioral intention is that of external PLOC (adoption: direct effect: 0.288 , indirect effect: 0.060; use: direct effect: 0.302 , indirect effect: 0.111$).^{10}$

An interesting observation emerges from a comparison of initial adoption (Figure 3) and experienced use (Figure 4) findings. Specifically, perceived usefulness and perceived ease of use are found to have no role as antecedents of attitudes or intentions for experienced use. Given the focus of OIT on internalization of behaviors, it seems that the endogenous motivations underlying the above user beliefs become integrated into attitude with increased experience. This finding seems to have important implications about "opening the black box of usefulness" by looking beyond technology to the users' endogenous motivations [4].

\section{Discussion and Implications}

RECENT RESEARCH [44] HAS ARGUED AGAINST the extrinsic-intrinsic dichotomy of system developer motivations in the context of open source software development. Specifically, Roberts et al. [44] argued that in contrast to this simplistic dichotomy, motivation may influence behaviors in more complex ways. For example, the researchers suggested that intrinsic and extrinsic motivations may coexist and may even complementarily influence behavior. Following prior user motivation research, though, they situated the locus of user motivation in tasks and environments external to the individual. For instance, Roberts et al. noted that the task of developing software is inherently motivating as it is complicated and creative. Also, they adapted the prior extrinsic motivation focus on external reward contingencies. Thus, though they draw upon related research by Deci [21, 22], Deci and Ryan [24], Ryan and Connell [46], and Ryan and Deci [50], they still presented a conceptualization of intrinsic and extrinsic motivations that was largely consistent with prior motivation research.

The research presented here builds on the work of Roberts et al. [44] to advance our understanding of user motivation beyond the intrinsic-extrinsic dichotomy. In addition to clarifying the theoretical understanding about "collections of motivations," this study situates the locus of user motivations inside the user, consistent with OIT [23].

OIT recognizes that a user's intentional response is a more precise indicator of behavior than the external environment or task characteristics. It conceptualizes motivations in terms of psychological perceptions of autonomy, freedom, conflict, and feelings of external pressure. By situating the locus of motivation and volition 
inside the user, it helps resolve the ambiguity about voluntary behaviors persistent in IT adoption research. By distinguishing whether user intentions are determined by internal PLOC, external PLOC, introjected PLOC, or a combination, it can precisely discern if behavior is volitional, mandatory, or introjected. Focusing primarily on internalized social values and personal values and beliefs-rather than social norms or external mandates - answers if a user wants to do what a referent thinks he or she should do because of that referent's influence, or because the act is consistent with the user's attitude $[18,62]$.

The extrinsic-intrinsic dichotomy has often treated extrinsic motivation typically in terms of external rewards, and in contrast, considered intrinsic motivation as being innate. However, our research suggests that it is perhaps more fruitful to focus on the volitional basis of internal PLOC. Specifically, even when not innate (intrinsic), some (identified) social values (typically those that are consistent with personal norms) can be internalized and consequently act as forcefully as intrinsic motivation. This suggests that the extrinsic-intrinsic dichotomy breaks down when there are similar levels of volition and autonomy as well as similar behavioral outcomes. Future research is recommended to further analyze extrinsic motivations that are complementary in nature to intrinsic motivations. Such research is also important for realizing how behavioral outcomes of external rewards may differ given feelings of volition versus external pressure perceived by the user. Our findings also indicate that whenever such external contingencies are considered, they must factor in users' personal values and internalized values.

Our study also developed a more in-depth theoretical and empirical understanding about introjected regulation, a critical issue rarely examined. Specifically, consistent with our theoretical framework, introjected PLOC stood out for its predominantly negative influence on user intentions, attitude, and key user beliefs. Our findings suggest that minimizing conflict between social norms and personal values deserves more research attention. Our empirical observations show that despite some positive role of external PLOC, the negative influence of introjected PLOC may sometimes override such benefits by a wide margin.

The results of our analysis summarized in Table 5 show that most hypotheses found empirical support. Two exceptions include H6 and H8 about external PLOC, which, as the weakest of the three motivational influences (i.e., three PLOC types), does not have any positive effect on user attitude or on perceived usefulness. It is likely that when feeling externally controlled and pressured, users internalize those values and associated behaviors that they most identify with. Similarly, when feeling externally controlled and pressured, they may become extremely resistant to those values and associated behaviors that conflict with their personal norms and values.

Comparing the standardized path coefficients and standardized effects reveals that with greater experience, internal PLOC and introjected PLOC tend to have greater (positive and negative, respectively) effect on intentions mediated by attitude. Hence, while both types of PLOC lead to attitudinal changes, external PLOC has more fleeting effect on users' attitude toward system use. The same rationale seems to apply to users' perceived usefulness of the system. In fact, both these effects (more specifically, their 
absence) seem interrelated - that is, what is not perceived as personally meaningful or relevant has a less lasting effect on attitude.

Consistent with the above discussion, with greater experience, introjected PLOC has greater indirect influence on intentions, mediated by attitude. Hence, H9 is not supported for experienced use given that over time such "negative" motivation becomes embedded in attitude and operates through it. Based on a review of standardized path coefficients (in Figures 3 and 4) and direct and indirect effects (in Tables 6), it appears that for both internal and introjected PLOC, attitude assumes a greater mediating role in affecting intentions with increased experience. Hence, focusing on internalized social and personal values highlights the role of attitude that seems obfuscated in research focusing on external influences.

Interestingly, introjected PLOC does not seem to have a significant direct effect on perceived usefulness (H12). Introjected PLOC's conflicted self-imposed feelings of coercion guide behavior predominantly through extreme external pressure. However, the instrumental concerns associated with perceived usefulness seem less relevant to this psychological state. Any effect that introjected PLOC exerts on perceived usefulness is mediated by perceived ease of use. ${ }^{11}$ The logic guiding this association is along the lines of: "I don't want to do it because I find it very pressurizing, so I find it less useful." With increased experience, internal PLOC plays a predominant role in affecting attitude as well as perceived usefulness. Hence, the secondary positive effect that perceived usefulness has on attitude at the time of initial adoption becomes nonsignificant with experienced use. The beliefs about perceived usefulness appear to be reinforced by feelings of personal volition and autonomy, become internalized in personal values, and operate through attitude. This may explain why H13 is not supported for experienced use.

Finally, this research study did not find support for the effect of perceived ease of use on attitude (H15). It sheds new light on how user attitudes and intentions are formed at initial adoption and shaped with experienced use. It appears that the endogenous motivations underlying perceived usefulness result primarily from internal PLOC. There seems to be an association between what one feels volitional and autonomous in doing and what one perceives as useful. Further, it appears that the (positive and negative) endogenous motivations underlying perceived ease of use result primarily from internal PLOC and introjected PLOC, respectively. Hence, these two PLOC types seem to significantly account for user beliefs associated with perceived ease of use and perceived usefulness. This is an important finding given the central role of these user beliefs in most IT adoption research as it helps understand their basis.

In summary, this study provides a fundamental theoretical understanding about endogenous user motivations as a basis for explaining and predicting user intentions. We developed the theoretical basis and empirical tests for clearly discerning if and when user intentions are determined by perceived external influences or personal volition. We empirically demonstrated that user intentions may result from "collections of motivations" based on different combinations of perceived external influences and personal volition. We also showed how user behaviors may be impeded by a conflict between perceived external influences and personal volition. Our theoretically grounded 
research model advances our prior understanding about user motivations by specifically focusing on user volition. It provides a theoretical and empirical basis for advancing theory and practice beyond focusing on extrinsic rewards and external mandates.

The findings of the study must be interpreted in light of its limitations. First, as our data analyses are cross-sectional rather than longitudinal, the posited causal relationships can only be inferred. Regardless, the cross-sectional analysis for both initial adoption and experienced use stages supports the proposed theoretical model. Second, because our analysis is limited to one specific IT implementation context in one organization, generalizability of the findings to other organizations and contexts requires further validation. However, given our focus on e-learning, the context of our study is consistent with the theoretical focus on personal development and growth. Third, given its endogenous focus, our theoretical frame treats all user behaviors as volitional. However, as we compared and contrasted both exogenous and endogenous antecedents, our model is inclusive and does not exclude nonvolitional behaviors.

Future research should focus on developing a more sophisticated context-sensitive understanding about endogenous motivations. Longitudinal analyses of adoption and use behaviors are recommended to investigate causal relationships. To understand the generalizability of the volitional behaviors posited by the OIT framework, different combinations of mandatory and volitional IT usage contexts need to be studied. Extensions of the current models to include analysis of usage data are also recommended.

\section{Conclusions}

TO YIELD EXPECTED INCREASES IN PRODUCTIVITY, new ITs need to be utilized effectively by highly motivated knowledge workers. Achieving this objective necessitates better understanding of how users' endogenous motivations influence their attitudes and intentions, as well as related beliefs, including perceived ease of use and usefulness. In the context of IT adoption and use, it is also important to understand how external influences (such as external mandates and extrinsic rewards) are appropriated and transformed into self-guided behavior. This study takes a step in that direction to help predict and explain how social norms and values are internalized as endogenous motivations and guide user intentions.

The proposed conceptualization of endogenous motivations highlights how system users' intentions are determined by their innate psychological needs for self-development and self-growth. Our theoretical framework developed new understanding about intrinsic and extrinsic motivations. Specifically, we broadened the notion of intrinsic motivation beyond pleasure-seeking hedonistic pursuits. Intrinsic motivation conceptualized in terms of internal PLOC was defined in terms of proactive pursuit of challenging and demanding opportunities toward the fullest development of human potential. Volitional pursuit of productive behaviors that may not be intrinsic but could be socially internalized was also conceptualized in terms of internal PLOC. The basis of both these motivations - intrinsic and extrinsic — rests on the fundamental theoretical understanding about system users' volitions and self-determined behaviors. By bridg- 
ing the extrinsic-intrinsic dichotomy, this study takes a small step toward a positive psychology of IT productivity, wherein work can be more fun [53, 61].

Acknowledgments: The first author acknowledges research support from the Robert H. Brethen Operations Management Institute, Earl V. Snyder Innovation Management Program, and the WSM Research Committee at the Syracuse University Whitman School of Management. Comments on prior versions of this paper by three anonymous referees and Robert Heckman and Jeffrey M. Stanton, both of the Syracuse University School of Information Studies, and the faculty participants at the Syracuse University School of Management's Management Information and Decision Sciences Colloquia are gratefully acknowledged.

\section{Notes}

1. It is important to note that our theoretical endogenous-exogenous distinction is completely unrelated to similar terms used in the causal modeling context to denote the direction of causality (i.e., exogenous being the predictor variables and endogenous being the predicted).

2. Note that "locus of causality" used in conjunction with perceived causality orientations is not the same as "locus of control." While locus of control is concerned with what controls a person's outcomes, locus of causality is concerned with why a person behaves as he or she does [23].

3. Perceived ease of use is defined as an individual's assessment that technology interaction will be relatively free of cognitive burden; the facility with which the individual is able to interact with a particular software artifact. Perceived usefulness is conceptualized as "the degree to which a person believes that using a particular system would enhance his or her job performance," where good performance was denoted by "raises, promotions, bonuses, and other rewards" [17, p. 320].

4. The above discussion assumes that there is no conflict between perceived external influences and personal norms and values of the user; hence, compliance results with minimal resistance. When there is strong conflict between perceived external influences and personal norms and values, that situation is distinguished as introjected PLOC, discussed later. In that scenario, resistance is relatively strong and may even result in rejection of the newly introduced behavior.

5. This assumes that there is no conflict between perceived external influences and personal norms and values of the user; hence, compliance results with minimal resistance and instrumental concerns about performance.

6. Some respondents listed the same self-derived and self-reported code for both surveys, others reported different codes for both surveys, and some chose not to report any code for one or both surveys.

7. Consistent with prior research, the initial adoption stage involves initial hands-on interaction of the subjects with the specific technology usually for the first time. In contrast, the experienced use stage denotes experienced longer-term interaction with the technology within a specific context of learning or work.

8. Identified reasons were captured, and found to involve acting from one's own values or goals, typically taking the form of "I want." Intrinsic reasons for action were included for behavior done simply for its inherent enjoyment, consistent with OIT.

9. To confirm our conceptualization of the three distinct constructs, we compared the CFA for three separate factors (internal PLOC, introjected PLOC, and external PLOC) and four separate factors (intrinsic PLOC, identified PLOC, introjected PLOC, and external PLOC). Only the three-factor model yielded an acceptable solution. The four-factor model showed that intrinsic PLOC and identified PLOC were so highly correlated that they both essentially represented the same underlying construct-that is, internal PLOC.

10. A variation of the research model that also included a direct path from perceived usefulness to behavioral intention was also analyzed. The less parsimonious model could not contribute to increased explanation or prediction of behavioral intentions. An examination of direct and indirect effects for this model still revealed internal PLOC as the primary (positive) determi- 
nant of behavioral intentions and attitude, and introjected PLOC as having a lesser but primary (negative) effect on behavioral intentions and attitude.

11. The significant negative effect of introjected regulation on PEOU should be interpreted very carefully given the potential possibility of a suppression effect.

\section{REFERENCES}

1. Ajzen, I., and Fishbein, M. Understanding Attitudes and Predicting Social Behavior. Englewood Cliffs, NJ: Prentice Hall 1980.

2. Anderson, J.C., and Gerbing, D.W. Structural equation modeling in practice: A review and recommended two-step approach. Psychological Bulletin, 103, 3 (1988), 411-423.

3. Bagozzi, R.P. The legacy of the technology acceptance model and a proposal for a paradigm shift. Journal of the AIS, 8, 4 (2007), 244-254.

4. Benbasat, I., and Barki, H. Quo Vadis, TAM? Journal of the AIS, 8, 4 (2007), 211-218.

5. Bentler, P.M. Comparative fit indexes in structural models. Psychological Bulletin, 107, 2 (March 1990), 238-246.

6. Bentler, P.M. On the fit of models to covariances and methodology to the bulletin. Psychological Bulletin, 112, 3 (November 1992), 400-404.

7. Bhattacherjee, A., and Sanford, C. Influence strategies for information technology acceptance: An elaboration-likelihood model. MIS Quarterly, 30, 4 (December 2006), 400-404.

8. Black, A.E., and Deci, E.L. The effects of instructors' autonomy support and students' autonomous motivation on learning organic chemistry: A self-determination theory perspective. Science Education, 84, 6 (2000), 740-756.

9. Browne, M.W., and Cudeck, R. Alternative ways of assessing model fit. In K.A. Bollen and J.S. Long (eds.), Testing Structural Equation Models. Newbury Park, CA: Sage, 1993, $445-455$.

10. Byrne, B.M. Structural Equation Modeling with AMOS. Mahwah, NJ: Lawrence Erlbaum, 2001.

11. Chinn, W.W. Issues and opinion on structural equation modeling. MIS Quarterly, 22, 1 (1998), vii-xvi.

12. Churchill, G.A., and Iacobucci, D. Marketing Research: Methodological Foundations. Cincinnati: South-Western College Publishing, 2001.

13. Cronbach, L.J., and Meehl, P.E. Construct validity in psychological tests. Psychological Bulletin, 52, 4 (1955), 281-302.

14. Csikszentmihalyi, M. Flow: The Psychology of Optimal Experience. New York: Harper and Row, 1990.

15. Csikszentmihalyi, M. Finding Flow: The Psychology of Engagement with Everyday Life. New York: Basic Books, 1998.

16. Csikszentmihalyi, M. Beyond Boredom and Anxiety: Experiencing Flow in Work and Play. San Francisco: Jossey Bass, 2000.

17. Davis, F.D. Perceived usefulness, perceived ease of use, and user acceptance of information technology. MIS Quarterly, 13, 3 (1989), 319-340.

18. Davis, F.D.; Bagozzi, R.P.; and Warshaw, P.R. User acceptance of computer technology: A comparison of two theoretical models. Management Science, 35, 8 (1989), 982-1003.

19. Davis, F.D.; Bagozzi, R.P.; and Warshaw, P.R. Extrinsic and intrinsic motivation to use computers in the workplace. Journal of Applied Social Psychology, 22, 14 (1992), 1111-1132.

20. DeCharms, R. Personal Causation: The Internal Affective Determinants of Behavior. New York: Academic Press, 1968.

21. Deci, E.L. Effects of externally mediated rewards on intrinsic motivation. Journal of Personality and Social Psychology, 18, 1 (April 1971), 105-115.

22. Deci, E.L. Intrinsic Motivation. New York: Plenum, 1975.

23. Deci, E.L., and Ryan, R.M. Intrinsic Motivation and Self-Determination in Human Behavior. New York: Plenum, 1985.

24. Deci, E.L., and Ryan, R.M. The "what" and "why" of goal pursuits: Human needs and the self-determination of behavior. Psychological Inquiry, 11, 4 (2000), 227-268. 
25. Deci, E.L., and Ryan, R.M. Handbook of Self-Determination Research. Rochester, NY: University of Rochester Press, 2002.

26. Deci, E.L.; Ryan, R.M.; and Williams, G.C. Need satisfaction and the self-regulation of learning. Learning and Individual Differences, 8, 3 (1996), 165-183.

27. Deci, E.L.; Eghrari, H.; Patrick, B.C.; and Leone, D.R. Facilitating internalization: The self-determination theory perspective. Journal of Personality, 62, 1 (March 1994), 119-142.

28. Dillman, D.A. Mail and Internet Surveys: The Tailored Design Method. New York: Wiley, 1999.

29. Fishbein, M., and Ajzen, I. Belief, Attitude, Intention, and Behavior: An Introduction to Theory and Research. Reading, MA: Addison-Wesley, 1975.

30. Fornell, C., and Larcker, D.F. Evaluating structural equation models with unobservable variables and measurement error. Journal of Marketing Research, 18, 2 (1981), 39-50.

31. Fornell, C., and Larcker, D.F. Evaluating structural equation models with unobservable variables and measurement error: Algebra and statistics. Journal of Marketing Research, 18, 3 (1981), 382-388.

32. Fornell, C.; Tellis, G.J.; and Zinkhan, G.M. Validity assessment: A structural equations approach using partial least squares. In B.J. Walker, W.O. Bearden, W.R. Darden, P.E. Murphy, J.R. Nevin, J.C. Olson, and B.A. Weitz (eds.), An Assessment of Marketing Thought \& Practice. Chicago: American Marketing Association, 1982, pp. 405-409.

33. Frankl, V.E. Man's Search for Meaning. New York: Washington Square Press, 1963.

34. Gagné, M., and Deci, E.L. Self-determination theory and work motivation. Journal of Organizational Behavior, 26, 4 (April 2005), 331-362.

35. Hartwick, J., and Barki, H. Explaining the role of user participation in information systems use. Management Science, 40, 4 (1994), 440-465.

36. Hu, L., and Bentler, P.M. Cutoff criteria for fit indexes in covariance structure analysis: Conventional criteria versus new alternatives. Structural Equation Modeling, 6, 1 (1999), 1-55.

37. Koestner, R., and Losier, G.F. Distinguishing three ways of being internally motivated: A closer look at introjection, identification, and intrinsic motivation. In E.L. Deci and R.M. Ryan (eds.), Handbook of Self-Determination Research. Rochester, NY: University of Rochester Press, 2002, pp. 101-121.

38. MacCallum, R.C.; Browne, M.W.; and Sugawara, H.M. Power analysis and determination of sample size for covariance structure modeling. Psychological Methods, 1, 2 (1996), $130-149$.

39. Malhotra, Y., and Galletta, D.F. Building systems that users want to use. Communications of the ACM, 47, 12 (2005), 88-94.

40. Malhotra, Y., and Galletta, D.F. A multidimensional commitment model of volitional systems adoption and usage behavior. Journal of Management Information Systems, 22, 1 (Summer 2005), 117-151.

41. Melone, N.P. A theoretical assessment of the user satisfaction construct in information systems research. Management Science, 36, 1 (1990), 76-91.

42. Nunnally, J.C., and Bernstein, I.H. Psychometric Theory. New York: McGraw-Hill, 1994.

43. Podsakoff, P.M.; MacKenzie, S.B.; and Lee, J.-Y. Common method biases in behavioral research: A critical review of the literature and recommended remedies. Journal of Applied Psychology, 88, 5 (2003), 879-903.

44. Roberts, J.; Hann, I.-H.; and Slaughter, S. Motivations, participation and performance in Open Source software development. Management Science, 52, 7 (2006), 984-999.

45. Rodriguez, D. Happiness and the art of innovation. BusinessWeek (March 6, 2006), 68-78.

46. Ryan, R.M., and Connell, J.P. Perceived locus of causality and internalization: Examining reasons for acting in two domains. Journal of Personality \& Social Psychology, 57, 5 (1989), 749-761.

47. Ryan, R.M., and Deci, E.L. The darker and brighter sides of human existence: Basic psychological needs as a unifying concept. Psychological Inquiry, 11, 4 (2000), 319-338.

48. Ryan, R.M., and Deci, E.L. Intrinsic and extrinsic motivations: Classic definitions and new directions. Contemporary Educational Psychology, 25, 1 (January 2000), 54-67. 
49. Ryan, R.M., and Deci, E.L. Self-determination theory and the facilitation of intrinsic motivation, social development, and well-being. American Psychologist, 55, 1 (2000), 68-78.

50. Ryan, R.M., and Deci, E.L. Overview of self-determination theory: An organismic dialectical perspective. In E.L. Deci and R.M. Ryan (eds.), Handbook of Self-Determination Research. Rochester, NY: University of Rochester Press, 2002, pp. 3-33.

51. Ryan, R.M.; and La Guardia, J.G. What is being optimized? Self-determination theory and basic psychological needs. In S.H. Qualls and N. Abeles (eds.), Psychology and the Aging Revolution: How We Adapt to Longer Life. Washington, DC: American Psychological Association, 2000, pp. 145-172.

52. Schwarz, A., and Chin, W. Looking forward: Toward an understanding of the nature and definition of IT acceptance. Journal of the AIS, 8, 4 (2007), 230-243.

53. Seligman, M.E.P.; Steen, T.A.; and Peterson, C. Positive psychology progress: Empirical validation of interventions. American Psychologist, 60, 5 (2005), 410-421.

54. Skinner, B.F. Science and Human Behavior. New York: Macmillan, 1953.

55. Sternberg, R.J. The theory of successful intelligence. Review of General Psychology, 3, 4 (December 1999), 292-316.

56. Tucker, L.R., and Lewis, C. A reliability coefficient for maximum likelihood factor analysis. Psychometrika, 38, 1 (March 1973), 1-10.

57. Vallerand, R.J. Toward a hierarchical model of intrinsic and extrinsic motivation. In M.P. Zanna (ed.), Advances in Experimental Social Psychology, vol. 29. New York: Academic Press, 1997, pp. 271-360.

58. Vansteenkiste, M.; Lens, W.; and Deci, E.L. Intrinsic versus extrinsic goal contents in self-determination theory: Another look at the quality of academic motivation. Educational Psychologist, 41, 1 (2006), 19-31.

59. Vansteenkiste, M.; Lens, W.; DeWitte, S.; DeWitte, H.; and Deci, E.L. The "why" and "why not" of job search behavior: Their relation to searching, unemployment experience and well-being. European Journal of Social Psychology, 34, 3 (2004), 345-363.

60. Venkatesh, V.; Morris, M.G.; Davis, F.D.; and Davis, G.B. User acceptance of information technology: Toward a unified view. MIS Quarterly, 27, 3 (September 2003), 425-478.

61. Wallis, C. The new science of happiness. Time (January 9, 2005), A2-A9 (available at www.time.com/time/magazine/article/0,9171,1015832,00.html).

62. Warshaw, P.R. A new model for predicting behavioral intentions: An alternative to Fishbein. Journal of Marketing Research, 17, 2 (May 1980), 153-172.

\section{Appendix: Constructs and Measurement Scales}

ITEMS WERE MEASURED USING A SEVEN-POINT LIKERT SCALE where $1=$ strongly disagree, $2=$ moderately disagree, $3=$ somewhat disagree, $4=$ neutral (neither disagree nor agree), $5=$ somewhat agree, $6=$ moderately agree, and $7=$ strongly agree.

Cronbach alpha reliabilities are listed for initial adoption and experienced use stages.

For PLOC items, each item was preceded by "I use the system ..." to capture the self-perceived "reasons" of behavior. For example, item 1 read: "I use the system because using the system is required by my course description."

Attitude $(\alpha=0.85$; use $=0.82)$

1. All things considered, my use of system in my course is a(n) Good/Bad idea

2. Scale with polar attributes: Negative, Positive

3. Scale with polar attributes: Wise, Foolish*

4. Scale with polar attributes: Harmful, Beneficial* 
Behavioral Intention $(\alpha=0.88$; use $=0.84)$

1. I intend to use the system in my course.

2. I intend to use the system for collaborating with others in my course.

3. I intend to use the system frequently in my course.

4. I intend to use the system for communicating with others in my course.*

5. I intend to use the system for coordinating tasks with others in my course.*

External PLOC $(\alpha=0.87 ;$ use $=0.84)$

1. ... Because using the system is required by my course description.

2. ... Because using the system is compulsory in my course.

3. ... Because my instructor requires me to use the system.

4. ... Because my instructor would think that I should use the system.*

5. ... Because I'll get in trouble if I don't use the system.*

6. ... Because that is what I'm supposed to do.*

7. ... So that my instructor wouldn't reprimand me.*

Internal PLOC $(\alpha=0.89 ;$ use $=0.86)$

Identified PLOC $(\alpha=0.79$; use $=0.90)$

1. ... Because I think it's personally important to myself.

2. ... Because I personally like using the system.

3. ... Because I want to understand how to use the system.*

4. ... Because I want to learn how to use the system.*

5. ... Because I want to find out if I am able to use the system.*

Intrinsic PLOC $(\alpha=0.81 ;$ use $=0.81)$

1. ... Because I enjoy using the system.

2. ... Because using the system is fun.

Introjected PLOC $(\alpha=0.93$; use $=0.95)$

1. ... Because it bothers me when I don't use the system.

2. ... Because I will feel bad about myself if I don't use the system.

3. ... Because I'll feel ashamed of myself if I don't use the system.

4. ... Because I want my colleagues to like me.

5. ... Because my friends would think that I should use the system.

6. ... Because my peers would think that I should use the system.

7. ... So that others won't get upset with me.

8. ... Because I want the instructor to think that I'm a good student.* 
Perceived Ease of Use $(\alpha=0.93$; use $=0.91)$

1. Learning to operate the system is easy for me.

2. I find it easy to use the system to do what I want to do.

3. My interaction with the system is clear and understandable.

4. I find the system adaptable for my interaction.

5. It is easy for me to become skillful at using the system.

6. I find the system easy to use.

Perceived Usefulness $(\alpha=0.93 ;$ use $=0.94)$

1. Using the system would improve my performance in my course.

2. Using the system in my course would enable me to accomplish tasks more quickly.

3. I find the system would be useful in my course.

4. Using the system would increase my productivity in my course.

5. Using the system would enhance my effectiveness in my course.

6. Using the system would make it easier to do my job.*

* Items with an asterisk were dropped as they had loadings of less than 0.70 on respective constructs. 